\title{
Land use/land cover changes and regional climate over the Loess Plateau during 2001-2009. Part I: observational evidence
}

\author{
Xingang Fan • Zhuguo Ma • Qing Yang • Yunhuan Han • \\ Rezaul Mahmood $\cdot$ Ziyan Zheng
}

Received: 26 March 2013 / Accepted: 5 January 2014 / Published online: 11 March 2014

(C) The Author(s) 2014. This article is published with open access at Springerlink.com

\begin{abstract}
Adverse environmental impacts from deforestation are a growing area of concern in climate change discussions. The Chinese government has implemented a series of policies, such as the Grain for Green Project, in an attempt to mitigate the impacts. This study takes a regional perspective to report land use/land cover changes over the Loess Plateau region from 2001 to 2009. MODIS data were used in analyzing both the conversions among and the resulting changes in different land types. Government statistical census data and observed climate data were also incorporated in the analysis. A general consistency is shown in both remotely sensed and census data. With the implementation of various projects, including the Grain for Green Project, the total
\end{abstract}

This article is part of a Special Issue on "Regional Earth System Modeling" edited by Zong-Liang Yang and Congbin Fu.

X. Fan· R. Mahmood

Meteorology Program, Department of Geography and Geology, Western Kentucky University, Bowling Green, KY 42101, USA

X. Fan

e-mail: xingang.fan@wku.edu

R. Mahmood

e-mail: rezaul.mahmood@wku.edu

X. Fan $\cdot$ Z. Ma $(\bowtie) \cdot$ Q. Yang $\cdot$ Y. Han $\cdot$ Z. Zheng

Key Laboratory of Regional Climate-Environment Research for Temperate East Asia, Institute of Atmospheric Physics, Chinese Academy of Sciences, Beijing 100029, China

e-mail: mazg@tea.ac.cn

Q. Yang

e-mail: yangqing@tea.ac.cn

Z. Zheng

e-mail: zhengzy@tea.ac.cn

Y. Han

University of Chinese Academy of Sciences, Beijing 100049, China

e-mail: hanyh@tea.ac.cn

R. Mahmood

Kentucky Climate Center, Western Kentucky University, Bowling Green, KY 42101, USA 
areas covered by grassland, cropland, and forests have increased by $19.2 \%\left(6.05 \times 10^{4} \mathrm{~km}^{2}\right)$, $33.7 \%\left(5.80 \times 10^{4} \mathrm{~km}^{2}\right)$, and $19.6 \%\left(3.08 \times 10^{4} \mathrm{~km}^{2}\right)$, respectively, during the 9-year period. While climatic conditions, particularly annual precipitation totals, usually dominate the distribution of vegetation, it is found that socioeconomic polices and human activities contribute to the increase in overall greenness and to vegetation growth (e.g., LAI increased by $16.8 \%(0.10)$ overall). However, the feedback of land use/land cover to regional climate is complicated and cannot be easily distinguished from natural climate variations based on short-term observational data alone. To better isolate the effects, further analysis and modeling studies are suggested.

\section{Introduction}

To address various types of natural disasters and environmental crises, China has implemented largescale reforestation/afforestation policies to contribute to a sustainable environment (e.g., Liu et al. 2008). The most well known government-funded program is the Grain for Green Project (GFGP), which focuses on the return of terrace-farming croplands to forests/grasslands with compensation from the state (e.g., Tao et al. 2004). This policy has resulted in large-scale redistribution of land-use rights and has been ongoing for more than a decade throughout China (Hvistendahl 2012). Some of the immediate benefits include increased vegetation coverage, soil erosion control, and reduced spread of wind-blown dust. However, additional longer-term and larger-scale ecological, environmental, and climatic impacts may also be occurring (Pielke 2005; Bonan 2008; Liu et al. 2008).

The Loess Plateau, located northeast of the Tibetan Plateau in northern China (Fig. 1), has garnered much attention due to its climate and land use/land cover (LULC) characteristics, and was chosen for a pilot GFGP in 1999 (Editorial Board of the China Yearbook 2002). It comprises a mix of arid, semiarid, and semi-humid areas, with an ecosystem that is sensitive and susceptible to climate transition due to global climate change (Liang et al. 2008). Drought, soil erosion, and desertification are ongoing concerns to local inhabitants whose agricultural activities and productivity rely largely on the availability of precipitation. The GFGP resulted in relatively rapid increase of overall greenness in early 2000s (e.g., Xin et al. 2008) and LULC changes are reported for many local counties (e.g., Cao et al. 2007; Wang et al. 2010; Zhou et al. 2012). This unique mixture of natural and artificially modified environments on the Loess Plateau serves as an ideal platform for the investigation of interactions between changes in ecosystem and climate (e.g., Cao et al. 2007; Liang et al. 2008).
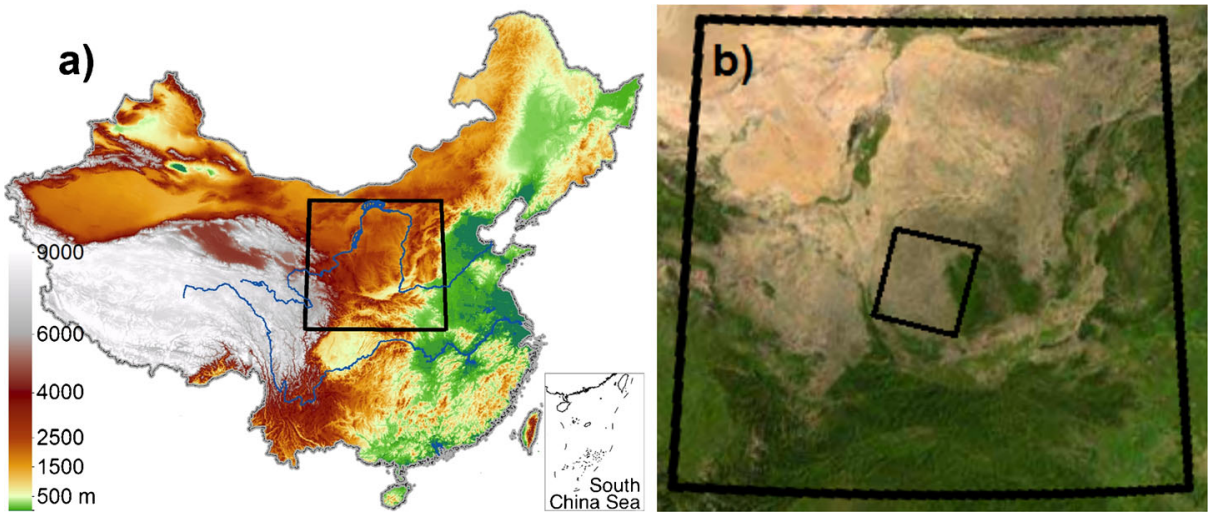

Fig. 1 Loess Plateau study area: a Topography and location of the study area, with the black box marking the 112.2× $10^{4} \mathrm{~km}^{2}$ area over $102-114^{\circ} \mathrm{E}$ and $32-41^{\circ} \mathrm{N}$; b Satellite view of the area (extracted from http://mapsof.net/uploads/ static-maps/china_satellite_photo.jpg); the small box marks the location where LandSat images are shown in Fig. 2 
The Chinese government has promoted a policy encouraging afforestation since the 1980s. This developed into the adoption of a more proactive step through the enforcement of a pilot GFGP on the Loess Plateau in 1999, including the provinces of Sichuan, Shaanxi, and Gansu; a nationwide GFGP was enacted in 2003. China invested about Chinese currency RMB 190 billion (equivalent of USD 23.2 billion) over a 10-year period (1999-2008) to subsidize farmers in regions with poor agricultural production or severe land erosion problems to enforce implementation of the GFGP, with an additional RMB 10 billion (USD 1.4 billion) pledged through 2015 (National Bureau of Statistics of China 2009b). Since the initial implementation of the GFGP in 1999, many studies have focused on its impacts at scattered local and small-regional scales. For example, Cao et al. (2007) reported that, in northern Shaanxi province, afforestation, along with the removal of livestock from over-grazed land, resulted in a large increase in the spatial coverage of trees and grasslands. Most of the existing studies take the perspective of overall changes in greenness or vegetation coverage over the region (e.g., Xin et al. 2008; Li et al. 2013). However, due to the nature of the GFGP as described above along with other human-induced afforestation efforts, the LULC change (LULCC hereafter) may also take the form of conversion among vegetation types. This study focuses on investigating at plateau-scale of these conversions and how they relate to regional climate.

To provide a qualitative idea and intuitive view of the change, Fig. 2 shows two natural-color satellite views of the area indicated in Fig. 1 b for 30 July 2000 and 23 July 2009. Due to different observation times, the colors in the western part of the area surrounding Sancha and north of Zhenyuan in Fig. 2b and the area east of Wang-chia-ho and Zhengning in Fig. 2a are affected by the sun angle. However, the areas in between, from Danbazhai and Yuan-cheng in the north down through QINGYANG and to Jingchuan, Ning Xian, and Zhengning in the south, show clear greening in 2009 than 2000. In the context of the aforementioned dynamic socioeconomic conditions (which contribute to LULCC), it is critical that we document the recent conversions and changes in LULC for further assessment of LULCC in China and its impact on regional climate, as well as feedback of climate to LULC and associated potential changes.

LULC data was retrieved from the Moderate Resolution Imaging Spectroradiometer (MODIS) (Strahler et al. 1999) on board the NASA Terra and Aqua satellites. MODIS LULC data include 17 classified land-cover types that were readily available for this study. This paper
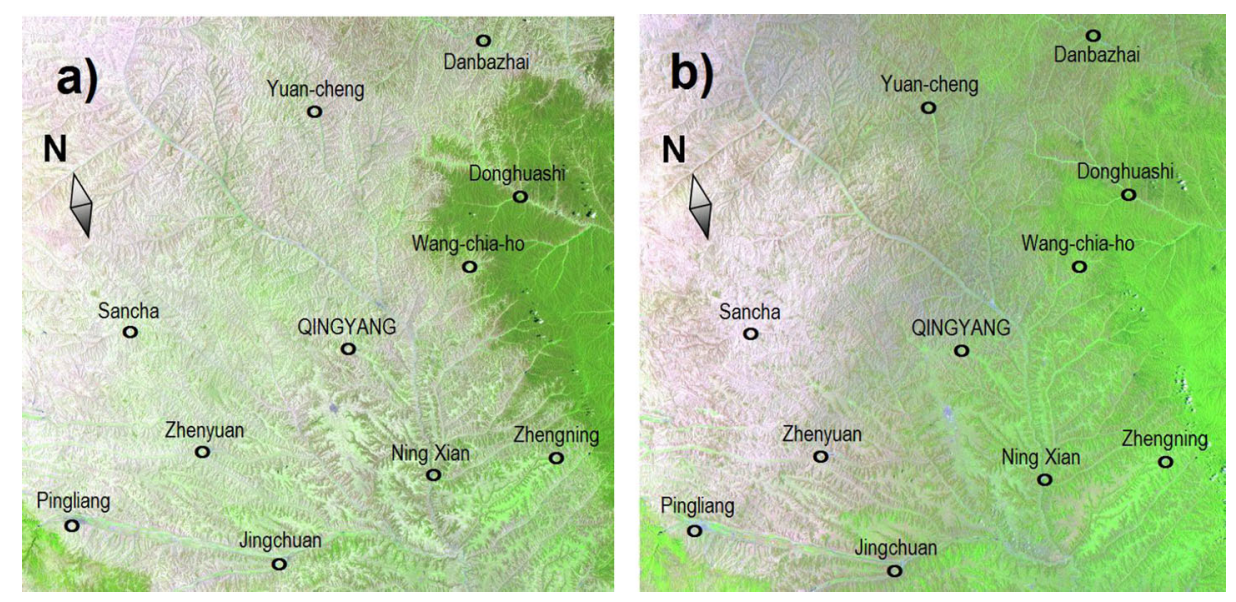

Fig. 2 Landsat 4-7 combined natural-color views of the area marked in Fig. 1b for: a 30 July 2000 and b 23 July 2009. The area is centered at $36.04^{\circ} \mathrm{N}$ and $107.7^{\circ} \mathrm{E}$ and covers an area of about $3.32 \times 10^{4} \mathrm{~km}^{2}$. Maps obtained from http://glovis.usgs.gov, LandSat 4-7 Multispectral Scanner, Thematic Mapper, and Thematic Mapper Plus combined product 
focuses on the changes to six major land-cover types, including bare ground, shrubland, cropland, grassland, woody savannah, and forest. These land types cover $98.5 \%$ of the Loess Plateau study area. Such LULCCs may have been directly impacted by government policy over the last decade, though there has heretofore been a lack of study of such changes in and conversions among the different land types, particularly at larger spatial scales.

Given the widespread human activities and resultant LULCC in the Loess Plateau region, as well as the availability of a decade-long high spatial-resolution LULC dataset, supplemented by Chinese governmental census data (ground-based human survey), the objectives of this study include:

1) Analysis of modern remotely sensed LULC data to document changes in and conversions among land-cover types that are related to the GFGP policy in the Loess Plateau region over the last decade, and

2) Validation of satellite-derived LULC data with census data to investigate the quality of both data sources and their consistency in revealing the source of the changes.

\section{Datasets}

MODIS data have been used to monitor terrestrial ecosystem processes due to their advanced radiometric and geometric properties (Strahler et al. 1999; Zhang et al. 2003, 2008). The MODIS land-cover data-product MCD12Q1 used in this study have a horizontal resolution of $500 \mathrm{~m}$, and were available annually from 2001 to 2009 .

In addition, MODIS-based leaf area index (LAI) data was used to quantify the coverage and changes of vegetation growth (NASA Land Processes Data Active Archive Center 2010; Yuan et al. 2011). LAI is defined as the total one-sided green leaf area per unit of ground area in broadleaf canopies, and as one-half total needle leaf surface area per unit of ground area in coniferous canopies. This dimensionless index is an indicator of the amount of available leaf material, and therefore reflects the canopy density and growth of vegetation (e.g., Kang et al. 2003; Hanes and Schwartz 2011). The LAI data have 1-km horizontal and 8-day temporal resolutions.

The other widely used index for vegetation greenness is the Normalized Difference Vegetation Index (NDVI), derived from the Advanced Very High Resolution Radiometer (AVHRR) on board the National Oceanic and Atmospheric Administration (NOAA) polarorbiting satellites (Goward et al. 1991; Myneni et al. 1997; Hargrove et al. 2009). NDVI is an indicator of the vegetative greenness of an area and, therefore, changes in NDVI can reveal changes in vegetation. NDVI data were available from 1981 to 2006 at 8 -km horizontal and 15-day temporal resolutions.

Observed precipitation and surface air temperature data from the China Meteorological Administration were used for regional climate analysis. Another important data source was the census data published annually by the National Bureau of Statistics of China (e.g., 2011, http:// www.stats.gov.cn/tjsj/ndsj/2011/indexeh.htm) and developed through direct ground-based human survey. This data were compiled by multiple governmental agencies from county, province, and up to national level based on divisions of administrative areas. For LULC, there are categories of total coverage areas of forests, grassland, cropland, urban development, as well as resulting total area of forests from specific projects and agricultural productivities. The LULCC for different land-cover types are derived from the annual data. 


\section{Regional climate over the Loess Plateau}

In northern China, the large-scale and long-term drying trend that has been ongoing since the 1970s has also been a primary characteristic of the climate trend in the Loess Plateau region ( $\mathrm{Ma}$ and $\mathrm{Fu}$ 2006; Ma 2007). Figure $3 \mathrm{a}$ and $\mathrm{b}$ show the climatology (based on 1961-90) and trends (based on 1961-2010) of mean annual precipitation and surface air temperature in the study area $\left(112.2 \times 10^{4} \mathrm{~km}^{2}\right)$. Figure $3 \mathrm{a}$ shows that for most $(69 \%)$ of the study area, mean annual precipitation falls below $600 \mathrm{~mm}$. The northwestern part (about $18 \%$ ) of the study area is arid, with mean annual precipitation less than $200 \mathrm{~mm}$. Mean annual precipitation increases southeastward. Its spatial distribution is closely correlated with the distribution of land use and vegetation types. Over the 50-year period 1961-2010, a significant wetting trend existed in the arid west, reaching a maximum of $43.1 \mathrm{~mm} / 10$-year. In contrast, a drying trend, reaching a maximum of $-39.5 \mathrm{~mm} / 10$-year, occurred over the central to the southern part of the study area (Fig. 3a). The climatology of mean annual surface air temperature (Fig. 3b) is primarily related to latitude and elevation (ref. Fig. 1a), ranging from 0.9 to $16.9{ }^{\circ} \mathrm{C}$ and increasing from north to south. The trend exhibits a
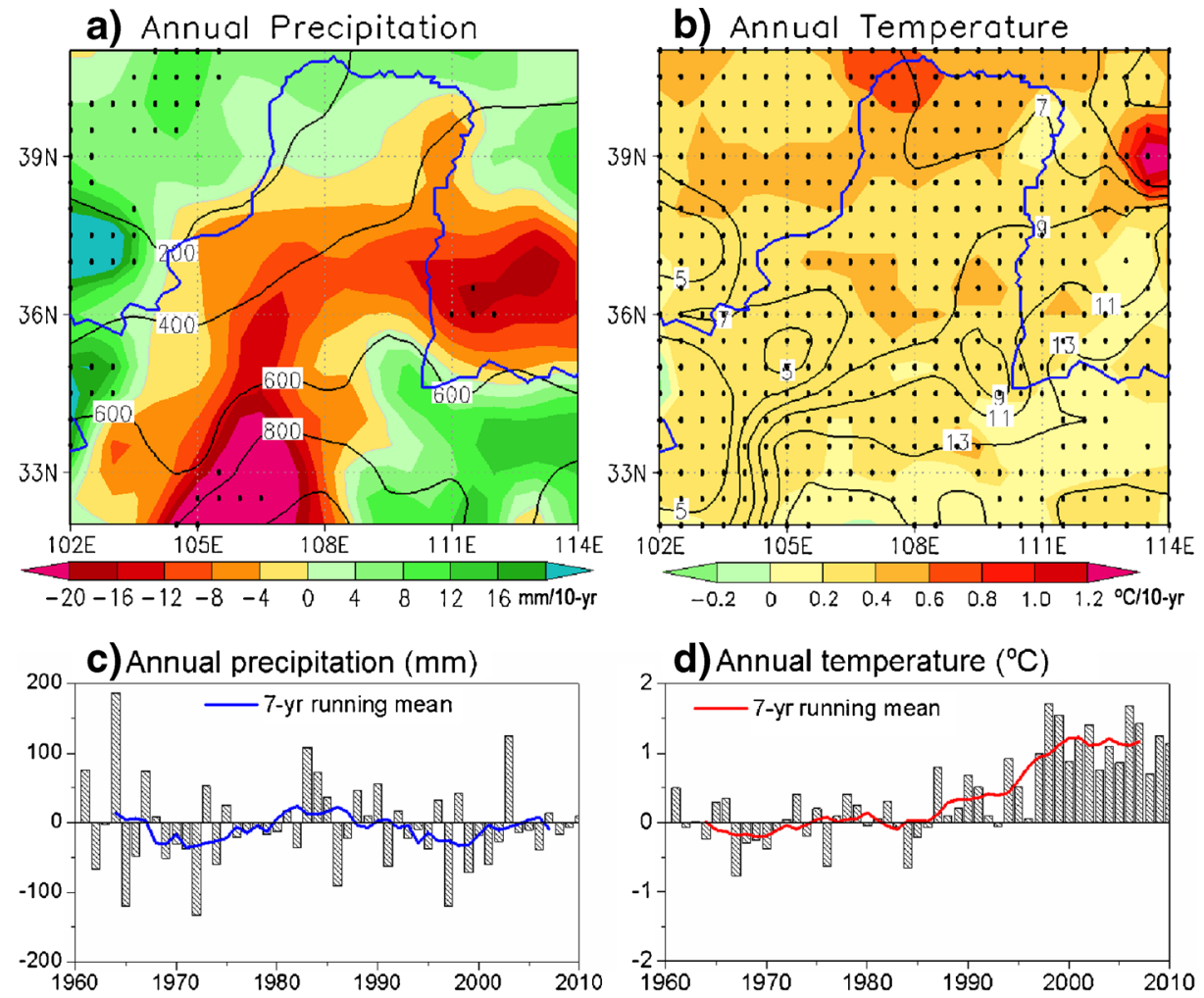

Fig. 3 a Mean annual precipitation ( $\mathrm{mm}$, solid contours) and trends ( $\mathrm{mm} \mathrm{10-year}{ }^{-1}$, shaded colors); b Mean surface air temperature $\left({ }^{\circ} \mathrm{C}\right.$, solid contours $)$ and trends $\left({ }^{\circ} \mathrm{C} 10\right.$-year ${ }^{-1}$, shaded colors $)$; c Time series of annual precipitation anomaly $(\mathrm{mm})$; d Time series of annual surface air temperature anomaly $\left({ }^{\circ} \mathrm{C}\right)$. Climatological means are based on the 30-year period 1961-90; trends are calculated over the 50-year period 1961-2010. Dotted areas in (a) and (b) show significance levels from student's $t$-test that exceed $95 \%$. Time series are averages over the entire study area. Superimposed curves in (c) and (d) are 7-year running means of precipitation and temperature, respectively 
significant warming, with a regional maximum of $1.5{ }^{\circ} \mathrm{C} / 10$-year over the 50 -year period, while the magnitude of the warming increases northward from 0.0 to $1.5{ }^{\circ} \mathrm{C} /$ 10-year. These results agree with those found in Wang et al. (2012), in which slightly different sub-regions were used.

In addition, Fig. $3 \mathrm{c}$ and $\mathrm{d}$ show the time series of the annual mean precipitation and surface air temperature anomalies, respectively. Precipitation (Fig. 3c) exhibits periods of strong variability in the 1960s, mid- to late 1980s, and late 1990s through 2003. Other periods were close to normal. Overall, more dry years than wet years occurred over this time period. It also appears that a recovery from a late-1990s dry spell has occurred over the last decade. Longterm variability of precipitation anomalies, after the shorter-scale variabilities were filtered with a 7-year running mean, shows a periodic fluctuation with a period of about 15-20 years. The surface air temperature anomaly (Fig. 3d) shows a clear warming trend. However, the trend declined somewhat from the late 1990s to 2010. Although these results show consistency with the findings of $\mathrm{Ma}$ and $\mathrm{Fu}$ (2006) in that a long-term drying trend started in late 1990s, the extended study period suggests a rebounding feature during the last few years.

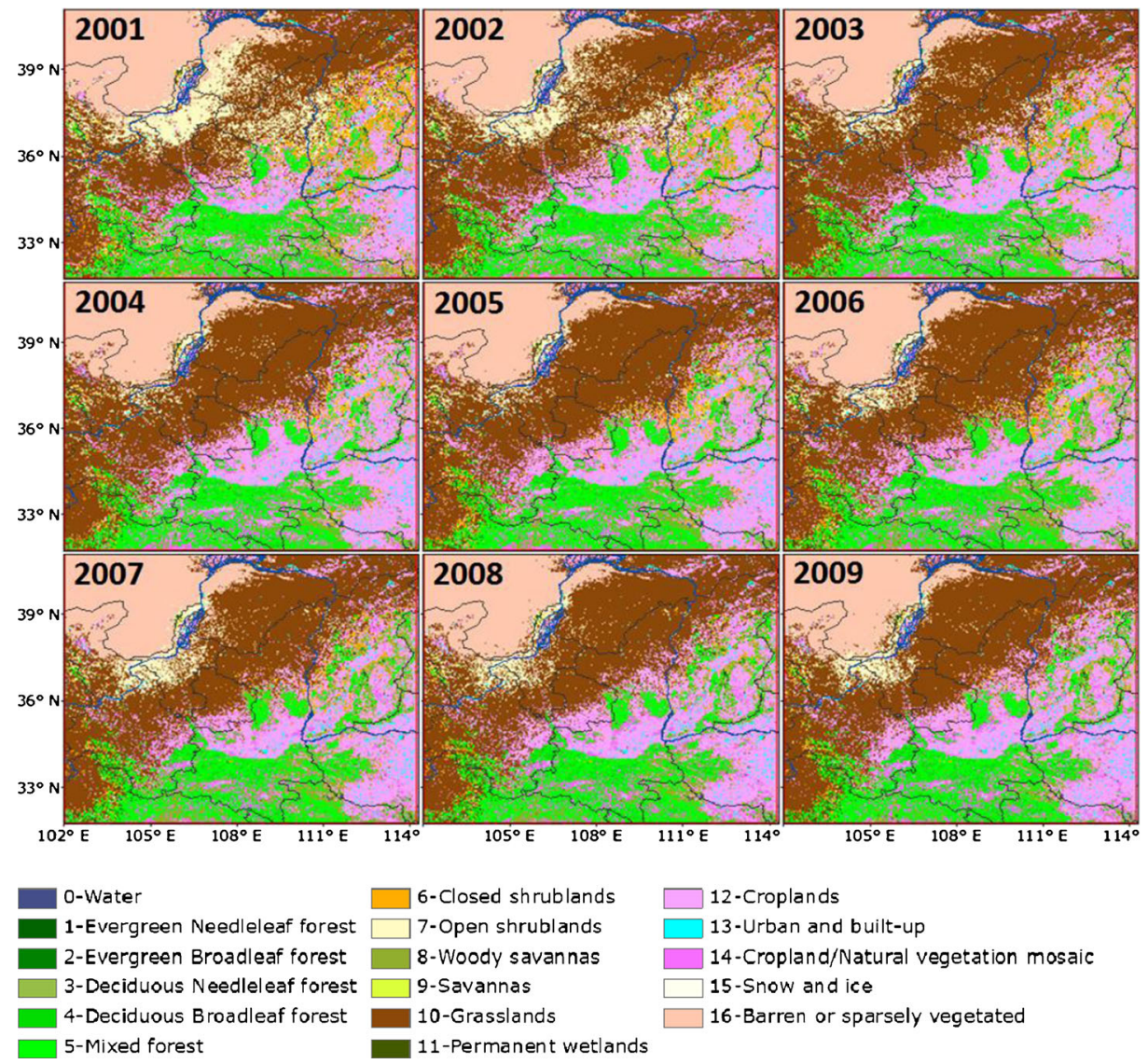

Fig. 4 MODIS-observed land use/land cover maps over the Loess Plateau for 2001-09, with 17 land-cover types shown 


\section{Land use/land cover change (LULCC) over the Loess Plateau}

\subsection{MODIS-observed changes}

Figure 4 shows MODIS-observed land-use maps for the Loess Plateau study area over the 9year period 2001-09. When averaged over the 9-year period, it was found that six types of LULC dominate the area. These LULC include grassland (32.9\%), croplands and cropland/ natural vegetated mosaic $(24.3 \%)$, forest $(15.0 \%)$, barren or sparsely vegetated land $(13.7 \%)$, open and closed shrublands (7.1\%), and woody savannah (5.5\%); in total, these represent about $98.5 \%$ of the study area. A comparison between Figs. 3a and 4 suggests that the distribution of these land-cover types is closely related to mean annual precipitation amounts (ref. contour lines in Fig. 3a). Barren ground or sparsely vegetated land were primarily found in the northwest of the study area, where mean annual precipitation was below $200 \mathrm{~mm}$. Grasslands were found in the area where mean annual precipitation was 200-400 mm. Cropland dominated in areas with precipitation above $400 \mathrm{~mm}$, which suggests the reliance of agriculture on precipitation. In the south-central part of the study area, forests were colocated with areas of precipitation above $800 \mathrm{~mm}$. The other three vegetation types, namely open shrubland, closed shrubland, and woody savannah, were found in the transition zones between barren lands and grasslands, grasslands and croplands, and croplands and forests, respectively.

During the 9-year period, the most obvious change evident from Fig. 4 was an increase in coverage of grasslands and croplands, along with a reduction of shrublands. The temporal change of total coverage area for each individual land type is shown in Fig. 5. While the areal coverage of the three major types, namely grassland, cropland, and forest, shows an increasing trend, the other three LULC types, including barren lands, shrublands, and woody savannah, show a decreasing trend. For the given study area, these changes imply that the increases in grassland, cropland, and forest occurred in adjacent areas formerly occupied by barren land, shrubland, and woody savannah. Overall, an increase in vegetation, as well as a greening of the study area has occurred over the last decade.

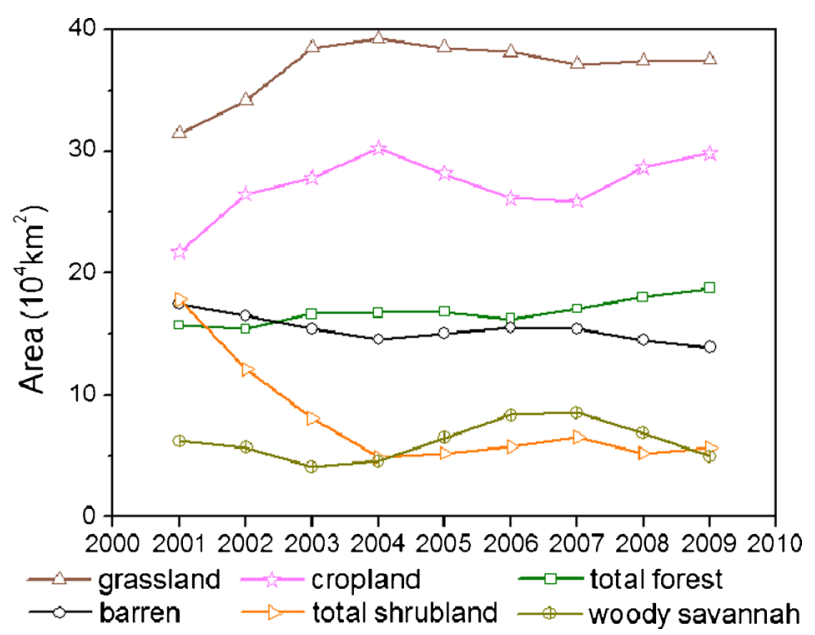

Fig. 5 Areal coverage $\left(10^{4} \mathrm{~km}^{2}\right)$ of grassland, cropland and cropland/natural vegetation mosaic, total forest, barren or sparsely vegetated land, open/closed shrubland, and woody savannah 
The interannual changes of the land covers show clear relationships with climatic conditions. For example, in addition to the warmer temperatures, precipitation gradually increased since 2000 and reached a peak in 2003 (Fig. 3c and d). The grassland, cropland, and forest show increases in areal coverage since 2000 and lasted about 2 years after 2003 (Fig. 5). A negative precipitation anomaly occurred in 2006. Correspondingly, the grassland, cropland, and forest areas decreased in 2006 and lasted into 2007. After the positive precipitation anomaly in 2007, a steady increase in these three land types took place since 2008. On the contrary, the coverage areas of barren land, shrubland, and woody savannah showed opposite changes.

The above LULCCs are also reflected in changes to LAI. Figure 6 shows the MODISretrieved LAI for the years 2000, 2005, and 2009 (Fig. 6a), along with their differences in Fig. 6b. The year 2005 was included due to the availability of both LAI and NDVI data, as well as the spatial precipitation pattern of 2005 is similar as that of 2000 (with a spatial correlation coefficient of 0.64). Figure 6a indicates that the 2005 area-averaged LAI was larger than that of 2000. Again, the 2009 LAI was greater than that of 2005 in most months except part of August and November. These results confirm the greening of the land demonstrated in Fig. 2. The LAI increase in both 2005 and 2009 relative to 2000 was seen throughout the entire year, with large differences present in the summer months of June through August. Compared to 2000, same level of LAI (e.g., leaf emergence period) appears earlier in 2005 and 2009. The

a) LAI vs. NDVI $(2000,2005,2009)$

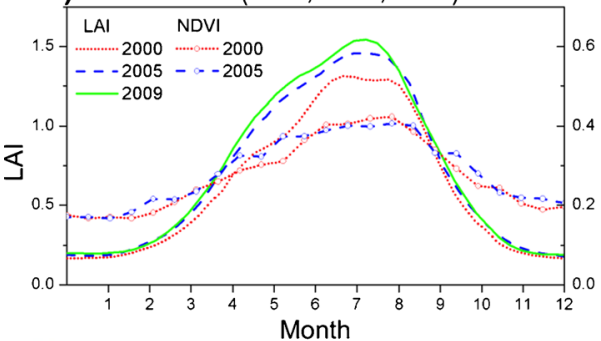

c) LAl - 21st 8-d period (2009-06-10 17)

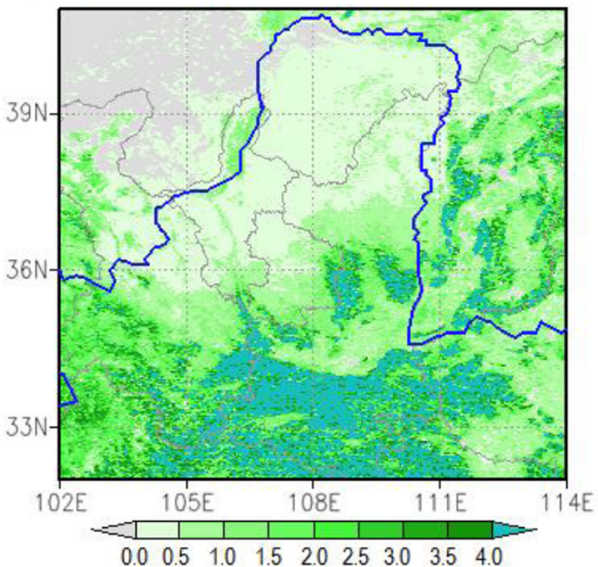

b) Differences from 2000

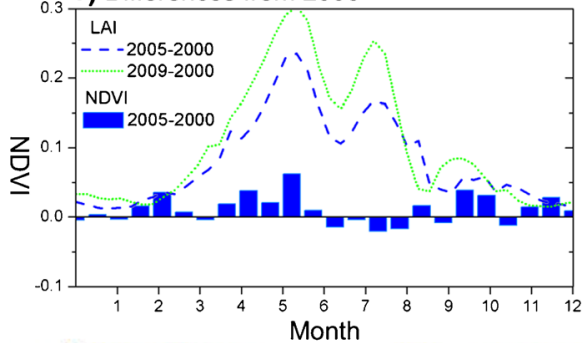

d) LAl difference - $(2009-2000) 21$ st $8-d$

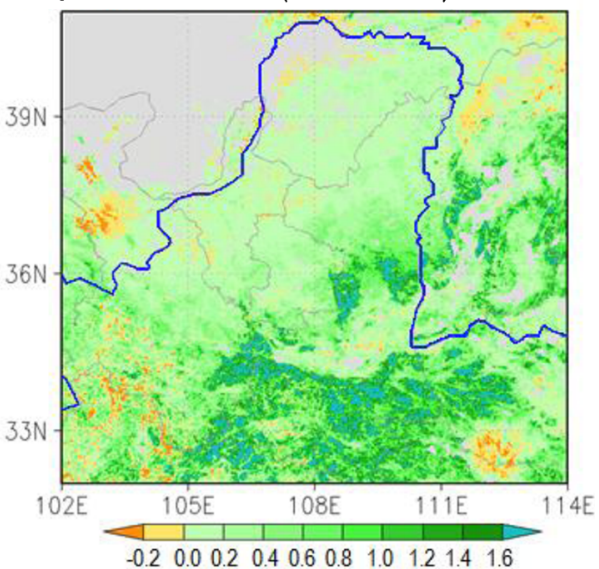

Fig. 6 a Monthly MODIS-observed LAI of 2000, 2005, and 2009 versus AVHRR NDVI of 2000 and 2005; b monthly differences of LAI and NDVI for 2005 and 2009 compared to 2000; c LAI of the 21st 8-day period of 2009 (10-17 June 2009); d LAI difference for the 21st 8-day period of years 2009 and 2000; Gray color in c and d indicate $\mathrm{LAI}=0.0$ in both 2000 and 2009 
larger difference between 2009 and 2000 suggests a continued greening after 2005. The maximum difference was found in the 21st 8-day period of the year, corresponding to 10 17 June (Fig. 6b). Figure 6c shows the LAI distribution of the 21st 8-day period in 2009. The difference map between 2009 and 2000 for the same period (Fig. 6d) shows that the majority of the study area has become greener by the end of the study period.

A comparison between 2005 and 2000 NDVI is also shown in Fig. 6a and b. Based on the definition of LAI and NDVI, their relationship changes with the leaf phenological periods (Wang et al. 2005). During leaf emergence and leaf production (greening) periods, there is a strong linear relationship between NDVI and LAI. During vegetative growth period, NDVI reaches maximum when LAI is above certain level. During leaf senescence period in autumn, NDVI decreases quicker than LAI. Figure $6 \mathrm{a}$ and $\mathrm{b}$ show greater LAI increase in the summer of 2005 and 2009 in comparison to 2000 than NDVI mainly due to that the NDVI became saturated (reaching its maximum) during the vegetative growth period.

\subsection{Human activity-related LULCCs}

In the Loess Plateau region, the primary human-related activities that affect LULCCs include farming, grazing, deforestation, and afforestation/reforestation. With the advent of the GFGP, some of the abandoned croplands were fenced in order to prevent over-grazing (Wang et al. 2010). Another reason for the abandonment of croplands in the last decade relates to changes in socioeconomic conditions because most of the agricultural activities in poorly developed rural areas rely on manpower; however, many young people migrated to big cities as reported by Wei (2008). Human activity-related LULCCs can therefore be inferred from an analysis of changes in cropland and total forest coverage, as well as the conversions from/to other LULC types.

Figure 7 shows changes in cropland area, including those going from cropland to other land-cover types and vice versa. For a given pixel, a change from cropland in a year to another type the next year, and never again reverting to cropland, was counted as a change from cropland to other land-cover types. On the other hand, a pixel that had never been cropland, but that became cropland in a year and maintained its cropland status in subsequent years, was said to have changed from other land-cover types to cropland. Changes from other land-cover types to cropland primarily reflect agricultural activities. As indicated previously, rainfall plays
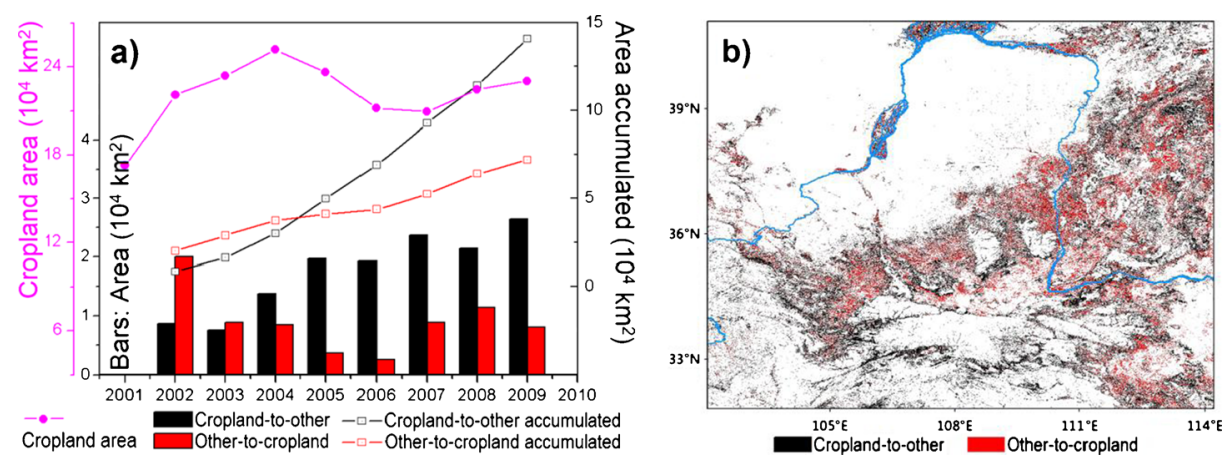

Fig. 7 Changes in coverage area between cropland and other land-cover types in the study area $\left(10^{4} \mathrm{~km}^{2}\right)$. a Annual change in areas (bars) and accumulated areas (black and red curves) over the study period; actual area of cropland (purple curve) shown for reference; b pixels $\left(1 \mathrm{~km}^{2}\right)$ that changed from cropland to other land types (black) and from others to cropland (red) 
a dominant role in the development of cropland in this semi-arid region. The annual changes from other land-cover types to cropland (red bars in Fig. 7a) follow the overall precipitation variations (Fig. 3c). The expansion of cropland, of course, contributed to an increase in the total area of cropland (purple curve in Fig. 7a). Over the 9-year period, the total accumulated changes from other land types into cropland were $7.21 \times 10^{4} \mathrm{~km}^{2}$ (red pixels in Fig. $7 \mathrm{~b}$ ). However, changes from cropland to other land types (black bars in Fig. 7a) exhibit a continuously increasing trend, which demonstrates little relationship to precipitation. The total accumulated changes from cropland to other land types were $14.08 \times 10^{4} \mathrm{~km}^{2}$ (black pixels in Fig. 7b), nearly double the other-to-cropland changes. These changes were most widespread in marginal cropland areas, though they occurred to a much lesser degree in other vegetated areas as well. This happened coincidently with the rapid expansion of the GFGP. An implication of human activity-induced (i.e., non-climatic) land-use change is revealed from the changes of cropland into other land types, which can be directly linked to the implementation of the GFGP (see discussions below about census data).

A similar approach is applied in analyzing changes to forest areas as shown in Fig. 8. Although deforestation can occur over a relatively short time period, afforestation requires a much longer period of time. During a given year, if a pixel that had never been forest in all previous years changed to forest and remained as forest, it was counted as a change from other land types to forest (i.e., afforestation/reforestation). On the other hand, pixels that were originally classified as forest and changed to and remained as non-forest were categorized as a change from forest to other types (i.e., deforestation). From Fig. 8a, we see that the amount of afforestation (red bars) was much larger than deforestation (black bars). The accumulated afforested area was about $3.54 \times 10^{4} \mathrm{~km}^{2}$ (red pixels in Fig. 8b), representing about three times the accumulated deforested area of $1.21 \times 10^{4} \mathrm{~km}^{2}$ (black pixels in Fig. 8b). Afforestation primarily occurred in the transition zones between cropland and forests, namely woody savannah areas, as well as on hilly slopes. Except for the relatively dry period of 2005-06, there was an overall increasing trend in the total forested area during the 2000s (red bars in Fig. 8a). This increasing trend is also supported by the census data from the National Bureau of Statistics of China (2009a, 2011), as shown in Fig. 9 and discussed below. This represents a relatively short time period for any potential climate-influenced expansion of forested areas, and we therefore suggest that this increase was primarily due to the land-use policy implemented by the Chinese government.
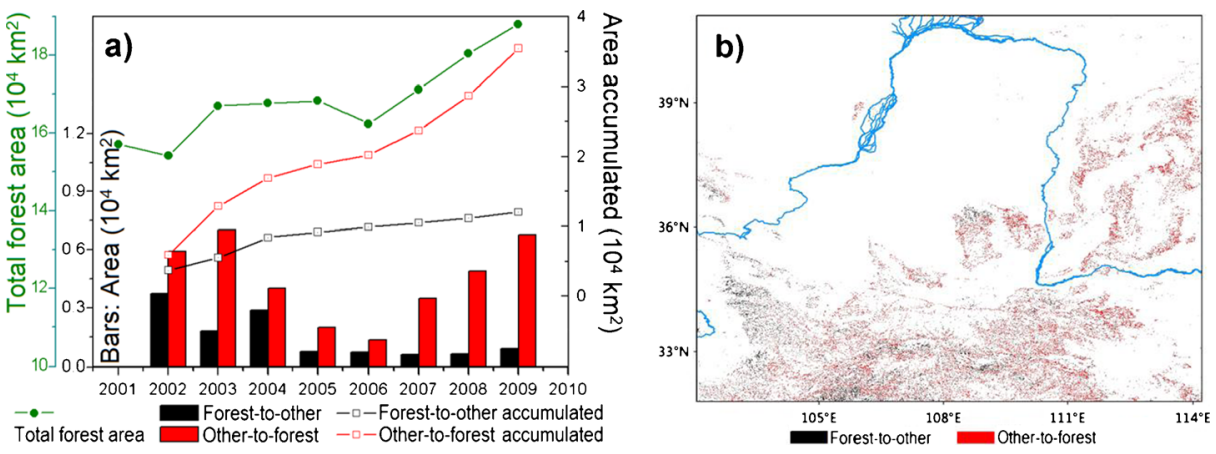

Fig. 8 Changes in coverage area between total forest and other land-cover types in the study area $\left(10^{4} \mathrm{~km}^{2}\right)$. a Annual change in areas (bars) and accumulated areas (black and red curves) over the study period; actual area of forest (green curve) shown for reference; b pixels $\left(1 \mathrm{~km}^{2}\right)$ that changed from forest to other land types (black) and from others to forest (red) 


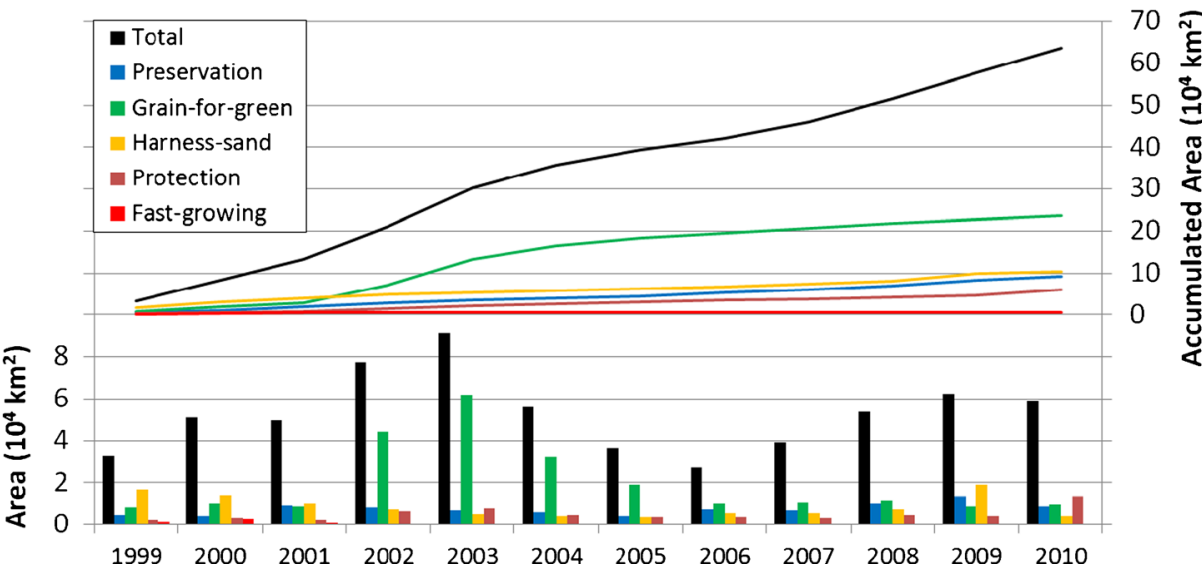

Fig. 9 Areas of key afforestation projects in China (in $10^{4} \mathrm{~km}^{2}$, or million hectares); Bars show the actual areas of afforestation for each year and each project; curves show the accumulations over time. Total includes the five key projects and other afforestation results; preservation signifies preservation of natural forests; Grain-for-green is the returning of croplands to forest; Harness-sand means the harnessing of source of sand and dust in the cities of Beijing and Tianjin; Protection is the protection forests in North China and the Yangtze River Basin; Fastgrowing signifies fast-growing timber forests. Data adapted from the National Bureau of Statistics of China (2009a, 2011)

Figure 9 shows the areas of afforestation that resulted from five key projects in China and reported in the census data. These projects include: Preservation of Natural Forests, GFGP, Harnessing of Source of Sand and Dust in the cities of Beijing and Tianjin, Protection forests in North China and the Yangtze River Basin, and Fastgrowing Timber Forests. Among the five projects, GFGP has contributed the most to newly forested areas. At the end of 2010, the accumulated total area of afforestation in China was about $6.4 \times 10^{5} \mathrm{~km}^{2}$ (64 million hectares), of which $37 \%$ resulted from the GFGP (Fig. 9; National Bureau of Statistics of China 2011). Interestingly, the annual total afforested areas, as well as the accumulations, resemble the results from MODIS-observed changes from other types to forest, as shown in Fig. 8a. The correlation coefficient between the annual other-to-forest conversion in Fig. 8a (red bars) and the annual total afforestation in Fig. 9 (black bars) is $R=0.91$, with a $99.0 \%$ confidence level in Student's $t$-test. It needs to be noted that the difference in magnitude between Figs. 8a and 9 is due to the fact that Fig. 8a represents results for the Loess Plateau study area alone, while Fig. 9 displays results for the entire country. In fact, the annual accumulations of the afforestation projects (curves in Fig. 9) exhibit even stronger correlations to the MODIS-observed accumulation of other-to-forest conversions (red curve in Fig. 8a). The correlation coefficient is $R=$ 0.93 (99.9\% confidence level) for the annual accumulation of GFGP, and $R=0.99$ ( $99.9 \%$ confidence level) for the annual total accumulation of all five afforestation projects. These results suggest that the MODIS-observed LULCCs are reliable. In addition, the consistency between MODIS data and government survey data implies that both data sources can support and supplement one another in regional climate studies. Although, as Bradley and Mustard (2004) pointed out, some variability in land productivity may be inherent to a dominant ecosystem, the high correlation of forest area changes shown in Figs. 8a and 9 implies that these changes are due to the active LULCC resulting from government policy and human activities. 


\section{Summary and discussions}

Over the past two decades (1990s-2000s), afforestation efforts have been attempted in order to mitigate the adverse impacts of climate change by reversing deforestation and desertification that have occurred in areas such as the Amazon rainforest, China during the Great Leap Forward movement in the 1950s, and other regions around the globe. In particular, China has implemented a series of projects including the GFGP. The resultant changes in vegetation coverage over the Loess Plateau were investigated. The study was primarily focused on identifying observed changes, while at the same time trying to establish links with regional climate. The analyses report:

1) A warming trend occurred throughout the entire study area over the past 50 years (19612010 ), with the amplitude of warming increasing from south to north and ranging from 0.0 to $1.5^{\circ} \mathrm{C} / 10$-year, and decreasing in the late $2000 \mathrm{~s}$. The annual precipitation showed a wetting trend in the arid west and a drying trend in the central to the southern parts of the study area. The maximum amplitudes were $43.1 \mathrm{~mm} / 10$-year for wetting and $-39.5 \mathrm{~mm} / 10$-year for drying. In the past decade, the late 2000s were relatively drier than earlier in the decade.

2) While vegetation types over the Loess Plateau generally depend on the distribution of annual precipitation, with temperature representing a secondary factor, LULC changes were notably affected by socioeconomic policies and human activities, including farming and/or implementation of the GFGP. The increase in vegetation coverage as a result of the afforestation effort was significant, and was supported by both census data and remotesensing data. For example, the accumulated change from cropland to other land-cover types during 2001-09 was $14.08 \times 10^{4} \mathrm{~km}^{2}$, representing $12.5 \%$ of the entire study area, and the accumulated change from other land-cover types to forest was $3.54 \times 10^{4} \mathrm{~km}^{2}$, representing $2.9 \%$ of the entire study area. The net increases in spatial coverage of grassland, cropland, and forest were $6.05 \times 10^{4} \mathrm{~km}^{2}(19.2 \%), 5.80 \times 10^{4} \mathrm{~km}^{2}(33.7 \%)$, and $3.08 \times 10^{4} \mathrm{~km}^{2}$ (19.6\%), respectively. A resulting net increase in LAI was 0.10 (16.8\%).

The interaction between regional climate and LULC is complicated, and yet is an important scientific subject that needs further attention (Pielke 2005; Mahmood et al. 2010). The impact of LULCC on climate is a long-debated question, as reviewed by Ellison et al. (2012). From this study we see the dominant role of climate on vegetation distribution and changes; however significant changes in LULC have occurred over the past decade due to human activities. Nevertheless, quantifying the feedback from changed LULC to the climate requires long-term data analysis. Furthermore, distinguishing the impacts of human activities from natural climate variations can be further investigated through the use of numerical modeling, which will help us to more fully understand how afforestation efforts contribute to regional and global climate. A preliminary study of the interactions between climate and LULC is presented in the accompanying work of Fan et al. (2014).

Acknowledgments This research was supported by the National Basic Research Program of China (2012CB956201), the National Natural Science Foundation of China (41275085), the Knowledge Innovation Program of the Chinese Academy of Sciences (KZCX2-EW-202), and the Special Fund for Meteorological Scientific Research in Public Interest (GYHY201106028). Jeremy Krieger at the University of Alaska Fairbanks helped editing and proofreading the manuscript.

Open Access This article is distributed under the terms of the Creative Commons Attribution License which permits any use, distribution, and reproduction in any medium, provided the original author(s) and the source are credited. 


\section{References}

Bonan GB (2008) Forests and climate change: forcings, feedbacks, and the climate benefits of forests. Science 320:1444-1449. doi:10.1126/science. 1155121

Bradley BA, Mustard JF (2004) Identifying land cover variability distinct from land cover change: cheatgrass in the Great Basin. Remote Sens Environ 94:204-213

Cao SX, Chen J, Chen L, Gao WS (2007) Impact of Grain for Green project to nature and society in north Shaanxi of China. Sci Agric Sin 40(5):972-979 (in Chinese)

Editorial Board of the China Yearbook (2002) The People's Republic of China Yearbook: achievements of the Grain for Green pilot program. China Yearbook Press

Ellison D, Futter MN, Bishop K (2012) On the forest cover-water yield debate: from demand- to supply-side thinking. Glob Chang Biol 18(3):806-820

Fan X, Ma Z, Yang Q, Han Y, Mahmood R (2014) Land use/land cover changes and regional climate over the Loess Plateau during 2001-2009. Part II: Interrelationship from observations. Clim Chang (this issue)

Goward SN, Markham B, Dye DG et al (1991) Normalized difference vegetation index measurements from the advanced very high resolution radiometer. Remote Sens Environ 35(2-3):257-277

Hanes JM, Schwartz MD (2011) Modeling land surface phenology in a mixed temperate forest using MODIS measurements of leaf area index and land surface temperature. Theor Appl Climatol 105(1-2): $37-50$

Hargrove WW, Spruce JP, Grasser GE, Hoffman FM (2009) Toward a national early warning system for forest disturbances using remotely sensed canopy phenology. Photogramm Eng Remote Sens 75: $1150-1156$

Hvistendahl M (2012) Turning over a new leaf in China's forests: a massive redistribution of land use rights aims to boost afforestation and sustainable forestry. Science 337(6090):26-27. doi:10.1126/ science.337.6090.26

Kang S, Running SW, Lim J et al (2003) A regional phenology model for detecting onset of greenness in temperate mixed forests, Korea: an application of MODIS leaf area index. Remote Sens Environ 86: $232-242$

Li S, Yan J, Liu X, Wan J (2013) Response of vegetation restoration to climate change and human activities in Shaanxi-Gansu-Ningxia Region. J Geogr Sci 23(1):98-112

Liang L, Lu SH, Shang LY (2008) Numerical simulation of effect of Loess Plateau vegetation change on local climate. Plateau Meteorol 27(2):293-300 (in Chinese)

Liu J, Li S, Ouyang Z et al (2008) Ecological and socioeconomic effects of China's policies for ecosystem services. Proc Natl Acad Sci U S A 105(28):9477-9482. doi:10.1073/pnas.0706436105

Ma Z (2007) The interdecadal trend and shift of dry/wet over the central part of North China and their relationship to the Pacific Decadal Oscillation (PDO). Chin Sci Bull 52(15):2130-2139. doi:10.1007/ s11434-007-0284-Z

Ma Z, Fu C (2006) Some evidences of drying trend over North China from 1951 to 2004. Chin Sci Bull 51(23): 2913-2925. doi:10.1007/s11434-006-2159-0

Mahmood R, Pielke RA Sr, Hubbard KG et al (2010) Impacts of land use land cover change on climate and future research priorities. Bull Am Meteorol Soc 91:37-46

Myneni RB, Keeling CD, Tucker CJ et al (1997) Increased plant growth in the northern latitudes from 19811991. Nature 386:698-702

NASA Land Processes Data Active Archive Center (LP DAAC) (2010) Leaf area index-fraction of photosynthetically active radiation 8-DayL4 global $1 \mathrm{~km}$ (MOD15A2), https://lpdaac.usgs.gov/lpdaac/products/ modis products table/leaf_area_index_fraction_of photosynthetically_active radiation/8_day_14 global_ $1 \mathrm{~km} / \bmod 15 \mathrm{a} 2, \overline{U S G S} /$ Earth Resources Observation and Science (EROS) Center, Sioux Falls, South Dakota

National Bureau of Statistics of China (2009a) China Rural Statistical Yearbook 2009, China Statistics Press

National Bureau of Statistics of China (2009b) The 60-year New China 1949-2009: Forestry, China Statistics Press

National Bureau of Statistics of China (2011) China Statistical Yearbook 2011, China Statistics Press, an online version was available at http://www.stats.gov.cn/tjsj/ndsj/2011/indexeh.htm (visited March, 21, 2013)

Pielke RA (2005) Land use and climate change. Science 310:1625-1626

Strahler A, Muchoney D, Borak J et al (1999) MODIS Land Cover and Land-Cover Change. MODIS Land Cover Product Algorithm Theoretical Basis Document (ATBD) Version 5.0. Center for Remote Sensing, Department of Geography, Boston University, Boston, MA

Tao R, Xu ZG, Xu JT (2004) Grain for Green Project, grain policy, and sustainable development. Soc Sci China 6:25-38 (in Chinese)

Wang Q, Adiku S, Tenhunen J, Granier A (2005) On the relationship of NDVI with leaf area index in a deciduous forest site. Remote Sens Environ 94:244-255 
Wang YS, Shi GH, Xu ZQ, Xu Q (2010) Study on the restoration process of enclosed grassland in Xilinguole. Pratacultural Sci 27(8):10-14 (in Chinese)

Wang QX, Fan XH, Qin ZD, Wang MB (2012) Change trends of temperature and precipitation in the Loess Plateau region of China, 1961-2010. Glob Planet Chang 92-93:138-147. doi:10.1016/j.gloplacha.2012.05.010

Wei LT (2008) Problems and countermeasures of new rural construction in Hebei Bashang region about returning cultivated land into forestry and pasture. J Hebei Agric Sci 12(8):143-146 (in Chinese)

Xin ZB, Xu JX, Zheng W (2008) Spatiotemporal variations of vegetation cover on the Chinese Loess Plateau (1981-2006): Impacts of climate changes and human activities. Sci China Ser D Earth Sci 51(1):67-78

Yuan H, Dai Y, Xiao Z et al (2011) Reprocessing the MODIS Leaf Area Index products for land surface and climate modelling. Remote Sens Environ 115(5):1171-1187

Zhang X, Friedl M, Schaaf C (2003) Monitoring vegetation phenology using MODIS. Remote Sens Environ 84(3):471-475

Zhang X, Sun R, Zhang B, Tong Q (2008) Land cover classification of the North China Plain using MODIS_EVI time series. ISPRS J Photogramm Remote Sens 63:476-484

Zhou DC, Zhao SQ, Zhu C (2012) The Grain for Green Project induced land cover change in the Loess Plateau: a case study with Ansai county, Shaanxi Province, China. Ecol Indic 23:88-94 